\title{
JORNADA DA SERVITIZAÇÃo DIGITAL: UMA ANÁLISE DAS PRÁTICAS E DESAFIOS EM UMA EMPRESA AUTOMOTIVA
}

Camila Favoretto (cam.favoretto@gmail.com) - Grupo de Estudo e Pesquisa em Serviços (GEPS), Universidade Federal de São Carlos (UFSCar).

Rafael da Silva Pereira (ㅁafael.pereira@uemg.br) - Grupo de Estudo e Pesquisa em Serviços (GEPS), Universidade Federal de São Carlos (UFSCar).

Glauco Henrique de Sousa Mendes (glauco@ dep.ufscar.br) - Grupo de Estudo e Pesquisa em Serviços (GEPS), Universidade Federal de São Carlos (UFSCar).

\section{RESUMO}

Servitização e digitalização são tendências que têm gerado mudanças nas empresas de manufatura. Da convergência entre elas surge um novo conceito: a servitização digital, entendido como um processo de transformação em que as empresas de manufatura mudam seus modelos de negócios centrados no produto para um orientado aos serviços com o suporte das tecnologias digitais. Este estudo tem como objetivo analisar a jornada da servitização digital percorrida por uma empresa automotiva e identificar as práticas e desafios durante este processo, além das principais ofertas de serviços digitais. Para isso, utilizou-se do estudo de caso único com entrevistas semiestruturas e a técnica de análise de conteúdo. Como resultado é apresentado à evolução da oferta dos serviços digitais ao longo do tempo e discutido a transformação organizacional da empresa a partir de quatro temas - motivação, estratégia, estrutura organizacional e processo.

Palavras chave: Servitização digital; Processo de transformação; Empresa automotiva.

\section{INTRODUÇÃO}

Empresas de manufatura estão sempre atualizando suas propostas de valor para satisfazer seus clientes (RADDATS et al., 2019). Essas propostas vêm sendo influenciadas pela ênfase em serviços (servitização), pelos investimentos em tecnologias digitais e pelas mudanças nos modelos de negócio, ou seja, essas empresas estão utilizando de meios digitais para adicionar serviços aos seus portfólios (GEBAUER et al., 2020; SJÖDIN et al., 2020). O conceito que 
destaca da convergência entre a digitalização e a servitização, é conhecido como servitização digital (SD) (GEBAUER et al., 2020; KOHTAMÄKI et al., 2020).

Muitos estudos (VENDRELL-HERRERO et al., 2017; BAINES et al., 2020; TRONVOLL et al., 2020) têm sido desenvolvidos buscando entender e conceitualizar a SD, porém, ainda faltam estudos sobre como as empresas de manufatura podem se tornar digitalmente servitizadas (KOHTAMÄKI et al., 2019; SKYLAR et al., 2019; TRONVOLL et al., 2020). A implementação da SD é um fenômeno complexo que exige grande esforço de transformação das empresas, não só em suas novas propostas de valor, mas em toda sua estrutura organizacional e modelos de negócios (VENDRELL-HERRERO et al., 2017; GEBAUER et al., 2020). Visando esta lacuna na literatura, este estudo parte do seguinte problema de pesquisa: Qual o processo de transformação organizacional seguido por uma empresa de manufatura para alcançar a servitização digital? Assim, este artigo tem o objetivo de analisar a jornada de implementação da SD em uma empresa automotiva e identificar práticas e desafios a partir de quatro temas - motivação, estratégia, estrutura organizacional e processos - além de apresentar as principais ofertas de serviços digitais ao longo desta jornada.

Para tanto, foi realizado um estudo de caso único com entrevistas semiestruturas, cujas análises foram feitas com base na técnica de análise de conteúdo. Deste modo, este artigo contribui para a pesquisa em SD de três maneiras. Primeiro, apresenta um exemplo empírico de implantação da estratégia de SD. Segundo, discute práticas e desafios relativos à implantação da SD. Terceiro, enfatiza aspectos da estrutura organizacional e dos processos operacionais que precisam ser reorganizados para a SD.

Além dessa introdução, o artigo está estruturado da seguinte forma: a seção 2 apresenta os conceitos que apoiam esta pesquisa. A seção 3 exibe a metodologia adotada e os resultados e discussões estão na seção 4. A seção 5 apresenta a conclusão identificando as contribuições do estudo além de suas limitações.

\section{REVISÃO TEÓRICA}

\subsection{Servitização digital}

O conceito da SD surgiu (VENDRELL-HERRERO et al., 2017; PASCHOU et al., 2020) 
devido à convergência entre a servitização e a digitalização (FRANK et al., 2019; GEBAUER et al., 2020). Na servitização, há a substituição do modelo transacional (focado na venda de bens tangíveis) pelo modelo relacional (focado em serviços) (BAINES et al., 2000). Por isso, a servitização é entendida como um processo de transformação organizacional (KOWALKOWSKI et al., 2017). A digitalização, por sua vez, refere-se à transformação dos processos de negócios pela aplicação de tecnologias, sobretudo as digitais (VERHOEF et al., 2019).

A literatura já reconhece uma forte conexão entre essas inovações e vem investigando-as de forma conjunta (por exemplo, FRANK et al., 2019; GEBAUER et al., 2020). Neste caso, a digitalização aprimora a servitização, estimulando a oferta de produtos inteligentes e serviços digitais. Enquanto, a servitização exige tecnologias digitais para entender as necessidades e processos dos clientes, coletar e trocar dados e melhorar as ofertas (KOHTAMÄKI et al., 2019).

Neste estudo, SD refere-se ao processo de mudança organizacional por meio do qual empresas de produtos implementam modelos de negócios orientados a serviços suportados por tecnologias digitais. No entanto, esse fenômeno ainda é incipiente, e até o momento, não há um entendimento claro de sua implementação (FRANK et al., 2019; KOHTAMÄKI et al., 2019; GEBAUER et al., 2020). Estudos recentes também enfatizam a necessidade de entender melhor a SD (PASCHOU et al., 2020; TRONVOLL et al., 2020). Assim, não está claro se as práticas utilizadas durante a jornada para SD e os desafios enfrentados diferem daqueles discutidos pela literatura sobre servitização e transformação digital (VERHOEF et al., 2019; GEBAUER et al., 2020).

\section{METODOLOGIA}

Como a SD é um fenômeno complexo e os estudos relacionados ainda estão em um estágio inicial, optou-se por realizar um estudo de caso único (YIN, 2009). Para seleção do caso foi utilizado uma amostragem intencional baseada em dois critérios: (i) a empresa deveria implementar a SD e, (ii) o caso fornecer acesso a informantes-chave e fontes secundárias. A empresa selecionada foi a "Alpha" (anonimizada para preservar a confidencialidade). Trata-se de uma manufatura multinacional localizada no Brasil desde 1957 e que está posicionada estrategicamente como integradora de produto, serviço e tecnologia no segmento automotivo 
de carros pesados (caminhão e ônibus), na qual oferta aos seus clientes soluções servitizadas e inteligentes, tendo como foco o segmento business-to-business - B2B.

\subsection{Coleta de dados}

A coleta de dados ocorreu de março a novembro de 2020, sendo auxiliada por um protocolo de coleta de dados, baseado em um roteiro com questões de pesquisa (YIN, 2009). Este roteiro foi fundamentado pela literatura sobre o tema e validado por meio de pré-testes com especialista acadêmicos. Os dados primários foram coletados por meio de entrevistas semiestruturadas (tanto pessoalmente quanto online). Pelo menos dois pesquisadores estiveram presentes em cada entrevista e as respostas foram capturadas por gravação de áudio (mais de 10 horas) e notas escritas. Foram realizadas quatro entrevistas com executivos da Alpha, além de uma entrevista com um representante da rede de concessionárias. Todos os respondentes estavam diretamente envolvidos com a jornada da SD e são descritos no Quadro 1. Transcrições escritas foram preparadas logo após cada entrevista.

Quadro 1: Descrição dos entrevistados

\begin{tabular}{|c|c|c|}
\hline Entrevistado & Cargo & Descrição \\
\hline E1 & $\begin{array}{l}\text { Gerente de portfólio } \\
\text { de serviços }\end{array}$ & $\begin{array}{l}\text { Atua há } 25 \text { anos no setor automotivo, atualmente é responsável por } \\
\text { todo o portfólio de serviços que é oferecido ao cliente final nas } \\
\text { concessionárias, incluindo serviços contratados, campanhas de vendas, } \\
\text { conectividade, entre outros. }\end{array}$ \\
\hline E2 & $\begin{array}{l}\text { Gerente de vendas } \\
\text { de frota }\end{array}$ & $\begin{array}{l}\text { Lidera uma equipe responsável pelo atendimento aos clientes de } \\
\text { grandes contas (key accounts) com geração de receita a partir da oferta } \\
\text { de soluções digitais. }\end{array}$ \\
\hline E3 & $\begin{array}{c}\text { Supervisor de } \\
\text { portfólio de serviços }\end{array}$ & $\begin{array}{l}\text { Responsável pelo desenvolvimento do portfólio de serviços e conexões } \\
\text { com outras iniciativas da organização, por exemplo, com a } \\
\text { digitalização (pacotes de programa de manutenção e soluções digitais). }\end{array}$ \\
\hline E4 & $\begin{array}{c}\text { Supervisor de } \\
\text { serviços digitais }\end{array}$ & $\begin{array}{l}\text { Desde } 2015 \text { é responsável pelo time de implementação dos serviços } \\
\text { digitais no Brasil. Esse time concentra as atividades de introdução em } \\
\text { escala exponencial de caminhões e ônibus conectados, além do suporte } \\
\text { a rede de concessionários. }\end{array}$ \\
\hline E5 & $\begin{array}{l}\text { Supervisor de } \\
\text { serviços em uma } \\
\text { concessionária da } \\
\text { rede }\end{array}$ & $\begin{array}{l}\text { Atua como supervisor do centro integrado de gestão de frotas, no qual é } \\
\text { responsável pela equipe de consultores de soluções (vendedores do } \\
\text { pacote produto-serviço-inteligência). }\end{array}$ \\
\hline
\end{tabular}

Como outras fontes de evidências (dados secundários) foram utilizadas materiais fornecidos pela empresa (portfólios, vídeos e apresentações) e outros disponíveis publicamente (página oficial da empresa na internet e aplicativos).

\subsection{Análises dos dados}


Para analisar os dados utilizou-se a técnica de análise de conteúdo, auxiliada pelo software NVivo Plus 11. Todos os pesquisadores envolvidos na coleta também participaram da codificação para análise paralela independente e triangulação (GIOIA; CORLEY; HAMILTON, 2013). O processo envolveu a leitura e codificação das transcrições das entrevistas, notas e dados secundários, seguido de comparação e cruzamento das informações (BAZELEY; JACKSON, 2013).

A Figura 1 resume o sistema de codificação usado para análise das entrevistas. Os códigos iniciais de primeira ordem foram baseados em fragmentos de texto extraídos das entrevistas. Eles representaram as práticas e desafios da implementação da SD. A codificação inicial rendeu cerca de 89 categorias; a recodificação subsequente para identificar semelhanças reduziu o número de categorias para 39. Ao identificar as relações entre esses códigos foi formulado 10 temas de segunda ordem, que foram nomeados com base na teoria (por exemplo, RADDATS et al., 2019). Em seguida, estes temas foram organizados em um nível superior de abstração, formando quatro temas agregados. 
Códigos de $1^{\text {a }}$ ordem

Novas receitas de serviços a partir de tecnologias digitais

Expansão de novos serviços digitalizados e habilitados digitalmente

- Aumento da representatividade do portfólio de serviços

Rede de concessionária precisou ser treinada e padronizada para os lançamentos

- Aumento da eficiência da frota pela redução de custos do cliente

- Produto mais competitivo por meio dos serviços oferecidos junto

Processos mais confiáveis gera fidelização

- É possivel coletar dados durante o ciclo de vida do produto

- Cliente precisa liberar a coleta de dados, ainda é um problema

- Tecnologia fornece visibilidade ao produto, sabe onde vai falh

- Com informaçōes consegue ser mais assertivo na tomada de decisão

- Oferecer serviços já era uma estratégia

- Serviços digitais são orientados a eficiência do produto

Clientes deixaram de pagar um valor fixo pela manutenção para pagar por disponibilidade - novos formas de contrato

- Clientes têm ganhos a partir das melhorias do produto

- Tecnologias todos possuem, o diferencial é conseguir oferecer inteligia de negócio Clientes no inicio não perceberam valor nos serviços digitais

\section{- Mudança de mentalidade}

- Cultura começou a valorizar os serviços digitais com negócio

- Cultura com valores voltados ao cliente e ao uso de dados

Cultura organizacional orientada aos serviços

- Mudança no foco dos relacionamentos entre atores internos e externo

Relacionamento baseado em cooperação organizacional

Integração organizacional

Agilidade nos processos precisou ser prioridade

Área de digitalização precisou ser reorganizada dentro da empresa

Unidade de serviços com mais importância para os negócios

Estrutura adaptáveis para seguir ágeis e com capacidade estratégica

Todos da empresa e rede de concessionárias alinhados com a estratégia

- Visão para o futuro clara e compartilhada

Estratégia direcionando as ações futuras de todos os niveis da empresa

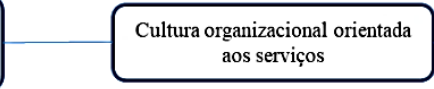

Abordagens colaborativas

Estruturas flexiveis e áreas

especificas

vindo de todos da empresa

Criação de novas fontes de receita

\section{Redução dos custos de transação}

e melhoria da eficiência

Capacidade de responder

rapidamente aos clientes

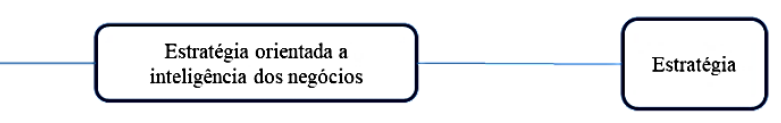

Desenvolvimento baseado em

dados e com mais elementos

Caminhão como portador de serviços

Informaçð̄es geradas pelo uso são a base das melhorias

Empresa precisou redesenhar o processo de desenvolvimento

Vendas com foco nas solução digitais ao invés do produto

Nova mentalidade para os vendedores, venda baseada no valor e não no preço

Vendedores são denominados como consultores de soluç̧⿸es

Treinamentos para desenvolvimento de novas competências e habilidade

- Conhecer o negócio do cliente passou a ser prioridade

Figura 1: Estrutura da codificação

\section{RESULTADOS E DISCUSSÕES}

Os resultados são apresentados seguindo a ordem dos temas agregados da Figura 1, usando citações dos entrevistados para ilustrar e comprovar as descobertas. Além disso, apresenta a jornada dos serviços digitais na Alpha.

\subsection{Oferta de serviços digitais na empresa Alpha}

A Figura 2 apresenta uma linha do tempo que mostra a oferta dos serviços digitais e serviços baseados na conectividade desenvolvidos pela empresa Alpha. A conectividade na empresa 
iniciou em 2016, por meio da implantação de dispositivos de conexão e comunicação nos caminhões. Isso permitiu ao transportador acessar dados do veículo via sistema e levou a empresa a oferecer os primeiros serviços digitais. Atualmente, a Alpha possui cerca de 35 mil veículos conectados no Brasil e 400 mil no mundo, gerando dados em tempo real. Alinhado com o objetivo de propor aos clientes pacotes de serviços digitais habilitados pelos dados, em 2017, a empresa lançou um programa de manutenção preventiva flexível, no qual o próprio sistema determina o momento de parada para manutenção baseado na leitura e análise contínua dos dados operacionais do uso do veículo. Dessa forma, a manutenção preventiva deixou de ser executada em intervalos fixos e periódicos por quilômetros rodados e passou a ser individualizada e personalizada, de acordo com a necessidade de cada veículo (operação, carga, estilo de condução, topografia, etc.). Portanto, o programa permitiu à empresa oferecer planos de manutenção sob medida, assegurando paradas rápidas (agendadas nas concessionárias) e assertivas (manutenção baseada em dados reais). Os clientes conseguiram reduzir gastos com reparos e até $75 \%$ menos do tempo de permanência do veículo na oficina.

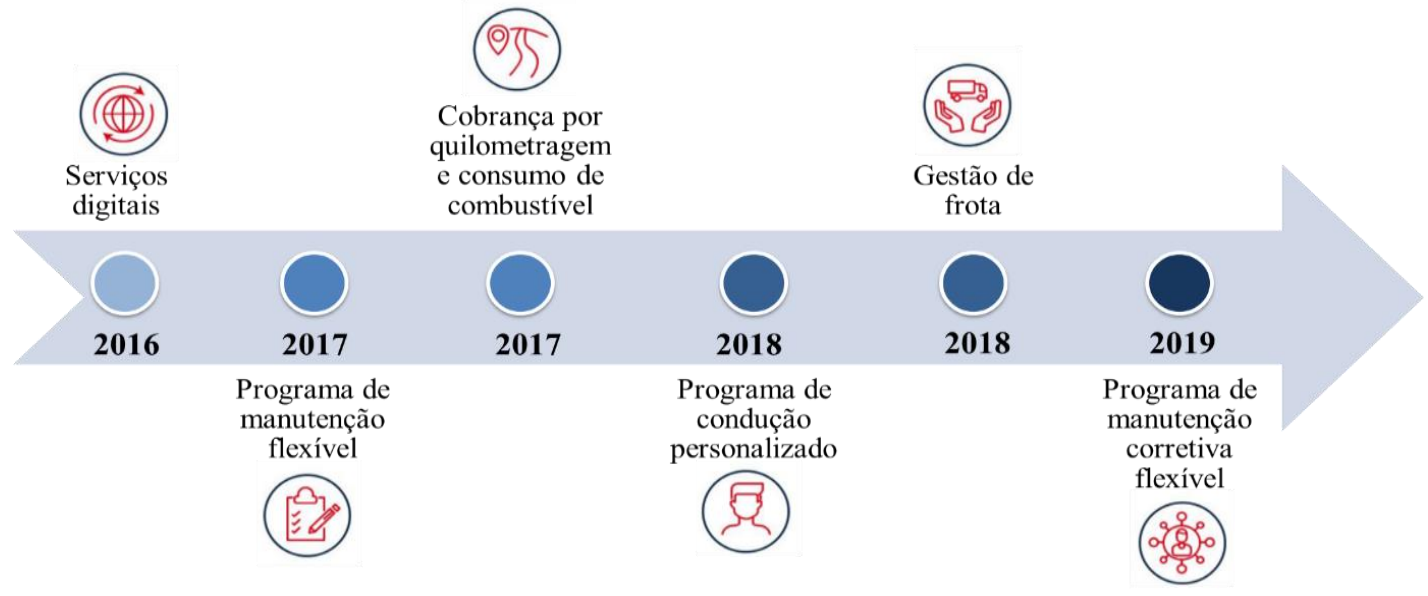

Figura 2: Jornada dos serviços digitais na Alpha

Todas essas inovações habilitaram à Alpha, ainda em 2017, a oferecer ao mercado um importante diferencial no custo de manutenção, a cobrança da manutenção por quilometragem, ou seja, o cliente paga o plano de manutenção de acordo com a distância rodada no mês, caso o caminhão fique parado, o custo é zero. Outro benefício foi a cobrança estar relacionada à faixa dinâmica de consumo de combustível - veículos que consomem menos entram em uma faixa que demanda menos paradas de manutenção preventiva e menores tarifas por quilometro rodado - o que pode gerar economia de até $25 \%$. 
Um ano depois, em 2018, os dados do uso dos serviços digitais pelos clientes forneceram à Alpha insumos para o lançamento de outro serviço, o programa de condução personalizado. Trata-se de um conjunto de serviços (treinamentos, orientações imediatas e relatórios) agora focados no motorista, podendo ser adaptado de acordo as informações de condução geradas pelos sensores e dispositivos no veículo (por exemplo, frenagem e aceleração). Os impactos positivos desse programa na operação dos clientes podem ser através da redução de consumo de combustível, menos desgaste dos componentes, mais tempo do veículo em operação, além da direção mais segura. Continuando a jornada dos serviços digitais, no final de 2018, a Alpha ofereceu mais um serviço orientado ao seu programa de manutenção preventivo, o gestor de frota, coordenado pela rede de concessionárias. O objetivo foi auxiliar o transportador no gerenciamento da sua frota através de um profissional dedicado e ferramentas digitais exclusivas de análise de dados capazes de orientá-lo. Os resultados são reais com uma média de $20 \%$ de aumento de disponibilidade e até $16 \%$ na redução dos custos de manutenção.

Por fim, em 2019, a Alpha inovou mais uma vez ao lançar serviços digitais para o programa de manutenção corretiva flexível, contemplando as manutenções preventivas e as corretivas de forma individualizada e personalizada, ou seja, o veículo avisa com antecedência o que deve ser trocado conforme os fatores operacionais controlados pela conectividade. Isso garante a máxima rentabilidade e confiabilidade operacional, buscando até $25 \%$ na redução de custos e aumento da disponibilidade da frota do cliente.

Por meio da jornada dos serviços digitais apresentada é possível verificar a missão da empresa na otimização de resultados dos clientes através do aumento de produtividade do veículo. Em contraste com os esforços de outras empresas do setor automotivo, em ofertar serviços digitais com foco na melhoria da experiência do cliente, a Alpha tem como estratégia adicionar serviços digitais e habilitados digitalmente no pós-venda e orientados ao produto, aumentando o valor percebido do cliente e gerando mais receita após a compra do veículo. Essa estratégia também permite que a empresa estenda o relacionamento com os clientes em outros pontos do ciclo de vida do produto e alcance maior fidelidade.

\subsection{Práticas e desafios ao longo da jornada da servitização digital}


A análise das entrevistas também permitiu identificar um conjunto de práticas e desafios na jornada da SD executado pela empresa Alpha, os quais estão apresentadas em síntese na Figura 3 e discutidas nos tópicos subsequentes.

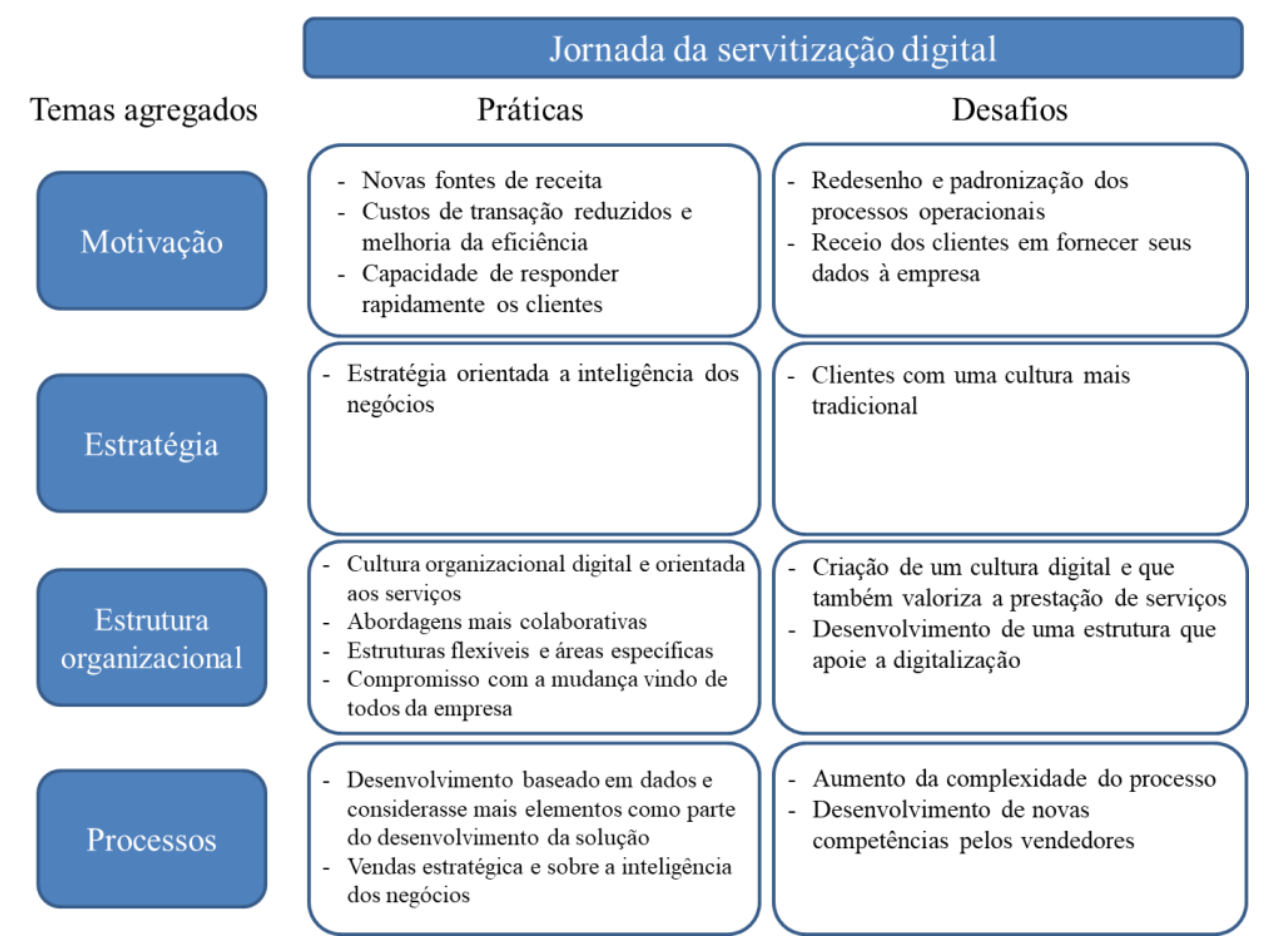

Figura 3: Práticas e desafios ao longo da jornada da SD

\subsubsection{Motivação}

Várias razões levaram a Alpha a adotar a SD. Entre elas, a empresa buscou por novas fontes de receita. Como apresentado na seção anterior, a digitalização permitiu a expansão do portfólio de serviços da empresa com novos serviços digitais e habilitados digitalmente (por exemplo, a gestão de frota). O E3 confirmou isso: “[...] nós tivemos um crescimento incrivelmente rápido que mudou nosso portfólio e a representatividade dele [...] de 2017 para hoje, nosso portfólio de serviços mais do que dobrou”. Porém, para alcançar novas fontes de receita, o uso de tecnologias digitais teve que ser acompanhado por um redesenho e padronização dos processos operacionais. O E5 assinalou como a Alpha superou esse desafio: "ela montou um grupo de funcionários e visitou cada concessionária da rede para padronizar todos os processos e preparar-nos para as novidades que vinham de digitalização, de telemetria, enfim".

Além disso, a Alpha foi motivada pela ideia de que a adoção de serviços digitais pode resultar em custos de transação reduzidos e melhoria da eficiência. No caso, essa redução afetou toda a cadeia de valor e gerou processos mais confiáveis também para os clientes. O E1 
afirmou: "Com a escala que temos e a customização dos planos de manutenção, posso ser muito mais eficiente, reduzir meu custo e tornar o produto muito mais competitivo [...] começamos a perceber a redução no consumo de combustível pelos clientes [...] isso gerou resultados para ele e quando gera resultado para o cliente gera fidelização e essa fidelização gera o meu ganho".

Outra motivação para a empresa foi melhorar a capacidade de responder rapidamente os clientes. $\mathrm{O}$ uso de tecnologias digitais fornece visibilidade ao produto, por exemplo, os sensores e dispositivos instalados no veículo podem diagnosticar as condições operacionais e emitir alertas sobre como o equipamento está ou quando irá falhar, permitindo a antecipação de ações e, consequentemente, garantindo tempos de respostas mais curtos e decisões mais assertivas. Sobre isso o E1 apontou: “Através do agendamento ativo [quando o sistema realiza diretamente o agendamento da manutenção] o concessionário já pode verificar seu estoque de peças e se preparar para quando o cliente chegar, em vez de demorar quatro horas para ser atendido, isso ocorrer em uma hora". Contudo, para se beneficiar da capacidade de fornecer respostas rápidas, a Alpha encontrou alguns desafios, entre eles, o receio dos clientes em fornecer seus dados à empresa, conforme afirmou $\mathrm{E} 2$ : " $O$ risco que nós corríamos era de o cliente achar que nós estávamos sendo invasivos porque nós estávamos pegando os dados dele". Para superar isso, a Alpha como estratégia, a princípio ofereceu os programas de manutenção somente para aqueles clientes menos tradicionais e formadores de opinião, que poderiam depois indicar e apontar as vantagens dos serviços digitais.

\subsubsection{Estratégia}

A busca pela SD influenciou a estratégia da Alpha. Durante as entrevistas ficou evidente que a empresa já possuía um foco em oferecer soluções (produtos, serviços e financiamento) para seus clientes, contudo, isso foi aprimorado e acelerado pela digitalização. A partir de 2016, a transformação digital estimulou o aumento e relevância do portfólio dos serviços para os negócios da empresa. Com mais informações sobre o uso do veículo foi possível construir uma base de dados precisa, permitindo novas propostas de valor orientadas a eficiência do produto (por exemplo, programas de manutenção preventiva flexível) e, consequentemente, aos resultados do cliente.

A digitalização permitiu a oferta de soluções mais avançadas, como os contratos baseados em resultados (disponibilidade), também focados na otimização dos resultados do cliente. Ou 
seja, a Alpha se voltou para uma estratégia orientada a inteligência dos negócios, este foi o diferencial, combinar informação, serviços e produto para apoiar um modelo de negócios baseado em soluções inteligentes que estimulam a melhoria de produtividade do cliente. O E3 comentou sobre isso: "Nós estamos vendendo produtos e serviços, mas muito focado na inteligência dos negócios, não é só o caminhão, não é só a reposição de peças, é como fazer com que o frotista possa tirar mais do caminhão dele, do negócio dele”. Portanto, em resumo, a estratégia da empresa se baseia em oferecer soluções digitais para auxiliar o cliente a ter uma maior eficiência e lucratividade. Contudo, de início isso não foi recebido com otimismo por seus clientes com uma cultura mais tradicional. Para esta situação, o E2 apontou: "Está sendo difícil vencer essa barreira, o cliente que a vida toda deu certo trabalhar daquele jeito [...] se pergunta, porque eu preciso mudar agora?".

\subsubsection{Estrutura organizacional}

Um tema relevante para a Alpha foi como reconfigurar sua estrutura organizacional para apoiar a jornada da SD. A primeira mudança foi o desenvolvimento de uma cultura organizacional digital e orientada aos serviços. O E3 confirmou a importância dessa transformação: "Nós mudamos a mentalidade, isso foi fundamental. Então, tivemos que abandonar a cultura de empresa que vende caminhões para ser uma prestadora de serviços". Mudanças nas estratégias relacionais foram necessárias. Assim, abordagens mais colaborativas precisaram ser desenvolvidas entre os atores da rede para estimular a aprendizagem mútua, cocriação e agilidade no desenvolvimento de novas ferramentas. Por exemplo, essa colaboração ocorreu entre as plantas do Brasil e Inglaterra conforme afirmou o E4: "Estamos buscando outras parcerias além da matriz, como nossas unidades são similares e precisamos de mais agilidade, estamos cortando alguns caminhos e fazendo uma cooperação com eles [planta da Inglaterra] para troca de informações e processos de desenvolvimento". Mudanças na configuração da estrutura organizacional também ocorreram na Alpha, estruturas flexíveis e áreas específicas para os serviços digitais foram formadas. Segundo o E3: “[...] de 2016 para 2017 essa área [digitalização] veio para serviços porque nós entendemos que pelas estratégias que vínhamos desenhando, naquele momento, fazia todo sentido ela se conectar com todas as soluções de serviços que nós estávamos propondo".

Por fim, o compromisso com a mudança vindo de todos da empresa, buscando garantir o alinhamento com a nova estratégia (orientada aos serviços digitais) também auxiliou a jornada da Alpha. Nas entrevistas o E1 confirmou: “[...] do nosso presidente até a organização e 
todos os concessionários pregam isso como visão, em ser líder em soluções digitais. Então por isso que provavelmente você vai ver a empresa [...] como pioneira em autônomos, tudo isso também pensando nesse posicionamento estratégico que nós buscamos". Portanto, aproveitar as vantagens da SD exigiu da Alpha formas organizacionais mais flexíveis, colaborativas e ágeis e, a empresa precisou legitimar essa transformação.

\subsubsection{Processos}

Para ser capaz de ofertar soluções digitais a Alpha precisou reconfigurar seu processo de desenvolvimento. Software e outros artefatos, como sensores e dispositivos se tornaram parte integrante do veículo e precisaram ser considerados neste processo. Além disso, as informações geradas durante o uso do caminhão servem como insumo para melhorias no produto e desenvolvimento de novos serviços que se adaptam melhor às necessidades dos clientes. Isso foi confirmado por E1: “A conectividade está ajudando muito na melhoria do produto e serviços. Agora a Engenharia é capaz de saber qual peça está quebrando e o que é possível melhorar para atender de forma eficaz o cliente". Portanto, a digitalização exigiu que a Alpha adotasse um novo desenvolvimento baseado em dados e considerasse mais elementos como parte do desenvolvimento da solução. Contudo, essas exigências trouxeram desafios com o aumento da complexidade do processo, devido a implementação das tecnologias digitais, o alto volume de dados capturados que carecem de análise para gerar conhecimento, além da necessidade de codesenvolvimento com clientes e parceiros.

A Alpha também precisou adaptar seu processo de vendas. Ele tornou-se mais estratégico e a inteligência dos negócios é o principal elemento da oferta, em vez de produtos ou serviços puros. Assim, a ênfase das vendas está na solução completa e não nas características exclusivamente técnicas do produto. Sobre isso o E2 acrescentou: "Estamos em uma fase de transição [...] hoje a área de vendas não é mais apenas uma área que vende caminhões - ela vende soluções. O vendedor que vai oferecer o caminhão, ele vai oferecer tudo conectividade, plano de manutenção, disponibilidade". Neste contexto, o principal desafio da Alpha foi o desenvolvimento de novas competências para os vendedores. Eles precisaram obter experiências também sobre os serviços (venda com base no valor), conhecimento mais detalhado das novas soluções oferecidas aos clientes e, em certos casos, conhecimento sobre os negócios dos clientes para conseguir sugerir uma proposta personalizada. Para enfrentar este desafio a Alpha elaborou um programa de treinamento para os vendedores das concessionárias. O E1 comentou sobre isso: "[...] foi necessário treinar mais de 400 
vendedores da rede, tanto em novas competências, conhecimento e habilidades, quanto no comportamento de trocar o "mindset", de passar de um vendedor baseado só em preço e ficha técnica do caminhão para ser um consultor de soluções".

\section{CONCLUSÃO}

O presente estudo contribui com a literatura existente, avançando em uma análise empírica sobre a transformação organizacional envolvida na jornada da SD por uma empresa de manufatura. Isso respondeu a nossa questão de pesquisa e jogou luz sobre três principais contribuições.

Primeira, a evolução da jornada dos serviços digitais só foi alcançada devido ao desenvolvimento de relacionamentos mais confiáveis e ofertas orientadas aos resultados dos clientes. A digitalização progressiva pode ser considerada uma facilitadora dessa jornada, mas, vai além, ela consegue transferir os serviços da periferia para o centro dos negócios. Segunda contribuição, a SD exige a adoção de um posicionamento estratégico orientado à inteligência dos negócios com foco na solução e não mais no produto puro. Essa nova perspectiva atua como mecanismo de legitimação para justificar a SD para as principais partes interessadas internas e externas. E por fim, para conseguir avançar com as ofertas de serviços digitais a empresa precisa reorganizar sua estrutura e processos, promovendo uma cultura digital e orientada aos serviços, maior integração e agilidade entre as áreas e unidades, além do compromisso de todos com a nova estratégia.

Apesar das contribuições, este estudo apresenta limitações. Embora o foco em um estudo de caso único auxilie o desenvolvimento da teoria, seria útil para trabalhos futuros a coleta de dados em outras empresas automotivas e até em outros setores para possíveis comparações e generalização dos resultados discutidos.

\section{AGRADECIMENTOS}

Agradecemos o apoio financeiro da CAPES e FAPESP e a empresa participante com as informações levantadas. 


\section{REFERÊNCIAS}

BAINES, T. et al. Framing the servitization transformation process: A model to understand and facilitate the servitization journey. International Journal of Production Economics, v. 221, p. $107463,2020$.

BAZELEY, P.; JACKSON, K. (Ed.). Qualitative data analysis with NVivo. 2013.

FRANK, A. G. et al. Servitization and Industry 4.0 convergence in the digital transformation of product firms: A business model innovation perspective. Technological Forecasting and Social Change, v. 141, p. 341-351, 2019.

GEBAUER, H. et al. Digital servitization: Crossing the perspectives of digitization and servitization. Industrial Marketing Management, 2020.

GIOIA, D. A.; CORLEY, K. G.; HAMILTON, A. L. Seeking qualitative rigor in inductive research: Notes on the Gioia methodology. Organizational research methods, v. 16, n. 1, p. 15-31, 2013.

KOHTAMÄKI, M. et al. Digital servitization business models in ecosystems: A theory of the firm. Journal of Business Research, v. 104, p. 380-392, 2019.

KOHTAMÄKI, M. et al. The relationship between digitalization and servitization: the role of servitization in capturing the financial potential of digitalization. Technological Forecasting and Social Change, v. 151, p. 119804, 2020.

KOWALKOWSKI, C. et al. Servitization and deservitization: Overview, concepts, and definitions. Industrial Marketing Management, v. 60, p. 4-10, 2017.

PASCHOU, T. et al. Digital servitization in manufacturing: A systematic literature review and research agenda. Industrial Marketing Management, v. 89, p. 278-292, 2020.

RADDATS, C. et al. Servitization: A contemporary thematic review of four major research streams. Industrial Marketing Management, v. 83, p. 207-223, 2019.

SJÖDIN, D. et al. An agile co-creation process for digital servitization: A micro-service innovation approach. Journal of Business Research, v. 112, p. 478-491, 2020.

SKLYAR, A. et al. Organizing for digital servitization: A service ecosystem perspective. Journal of Business Research, v. 104, p. 450-460, 2019.

TRONVOLL, B. et al. Transformational shifts through digital servitization. Industrial Marketing Management, v. 89, p. 293-305, 2020.

VENDRELL-HERRERO, F. et al. Servitization, digitization and supply chain interdependency. Industrial Marketing Management, v. 60, p. 69-81, 2017. 
VERHOEF, P. C. et al. Digital transformation: A multidisciplinary reflection and research agenda. Journal of Business Research, v. 122, p. 889-901, 2019.

YIN, R. K. Case study research: Design and methods. Sage Publications, Thousand Oaks, v. 5, 2009. 